\title{
Observing the Oceans from the COOL Room: Our History, Experience, and Opinions
}

\author{
Scott Glenn and Oscar Schofield \\ Rutgers University. New Brunswick, New Jersey USA
}

This is an exciting time for oceanography. We as a community are poised to pursue scientific problems that have challenged oceanographers for over 50 years while simultaneously giving back to the society that pays the bill for ocean research. New observational technologies and significant advances in numerical modeling enable these potential breakthroughs. The continued development of long-term monitoring, adaptive sampling, and dynamical forecast systems will especially enhance our understanding of the processes occurring on continental shelves, which are dynamic in space and time, difficult to sample using traditional techniques, and are subject to increasing pressures from human activity. Our optimism is based on the accelerating pace at which champions within federal agencies have garnered support, and by our decade long experience in observing and modeling New Jersey's coastal ocean, where we have been fortunate to glimpse what is possible. Our efforts began in 1993 with a single S4 current meter/CTD, which, through collaborations with an incredibly long list of partners, has evolved into the shelf-wide New Jersey Shelf Observing System (NJSOS) (Figure 1). This manuscript highlights our history, what we have learned, and what hurdles we feel need to be cleared for building a truly integrated and sustained network of ocean observatories capable of delivering on their potential to a user community that includes scientists, businesses, regulators, and the general public.

\section{Evolution of the Observatory}

The vision for developing a "permanent window to the sea" was that of Frederick Grassle and Christopher von Alt, legend has it on a barroom napkin in 1986. It was a vision that entrained us, and several others, as junior faculty in the formative years of Rutgers University's new Institute of Marine and Coastal Sciences. In the early 1990s, Rutgers re-occupied a designated research area offshore Tuckerton that had been abandoned since the middle 1970s but was still found on the NOAA navigation charts. The approximately 3 by $3 \mathrm{~km}$ box was the proposed site of an offshore floating nuclear power plant in a plan developed in response to that decade's energy crisis. Joint Rutgers and Woods Hole Oceanographic Institution efforts initially focused on deploying a cabled ocean observatory in 15 meters water depth and also on developing small robust autonomous underwater vehicles (AUVs). The strategy was based on scienceengineering partnerships where the scientist provided the motivation, the engineer developed the new tools, and the team collaborated on implementation. This model has been central to the growth of the New Jersey observation network, where science-engineering partnerships have focused on the development of satellite data-processing algorithms (Moline et al., 2003), surface current radars (Kohut et al., 1999; Kohut et al., in press), autonomous underwater gliders (Schofield et al., 2002, 2003), ship-towed systems (Creed et al., 1998; Creed and Glenn, 2000), and bio-optical instrumentation (Kirkpatrick et al., 2003). The partnerships were the key to ensuring success as all projects were funded through competitively awarded research grants.

The spatial sampling capabilities offshore New Jersey have evolved from this kilometer scale box for the Long-term Ecosystem Observatory (LEO) in the early to middle 1990s, through the tens of kilometer scales of the Coastal Predictive Skill Experiments (CPSEs) in the late 1990s, and are now hundreds of kilometers in the present NJSOS. To those readers similarly inculcated in the Harvard ocean forecasting experience, this spatial progression will be recognized as the strategy Alan Robinson used to successfully develop the capability to forecast the energetic mesoscale dynamics of the deep ocean. That strategy, in simple terms, was to first correctly resolve a small piece of the ocean, and then expand in space. This recognizes the basic fact that we typically over-sample in time (Figure 2) and undersample in space. It emphasizes that to increase our understanding of fundamental processes as required to predict the future, we need spatially coherent data so we can map the resulting structures as they evolve in time. If your data is not spatially coherent, you can't resolve the spatial gradients for the dynamical balances, and all you have are independent time series of what happened, but not why.

\section{Benthic Processes at LEO-15 (3m by 3m)}

Early research focused on multi-disciplinary processes that operated on a shore-oblique sand ridge present in the ubiquitous ridge and swale topography 


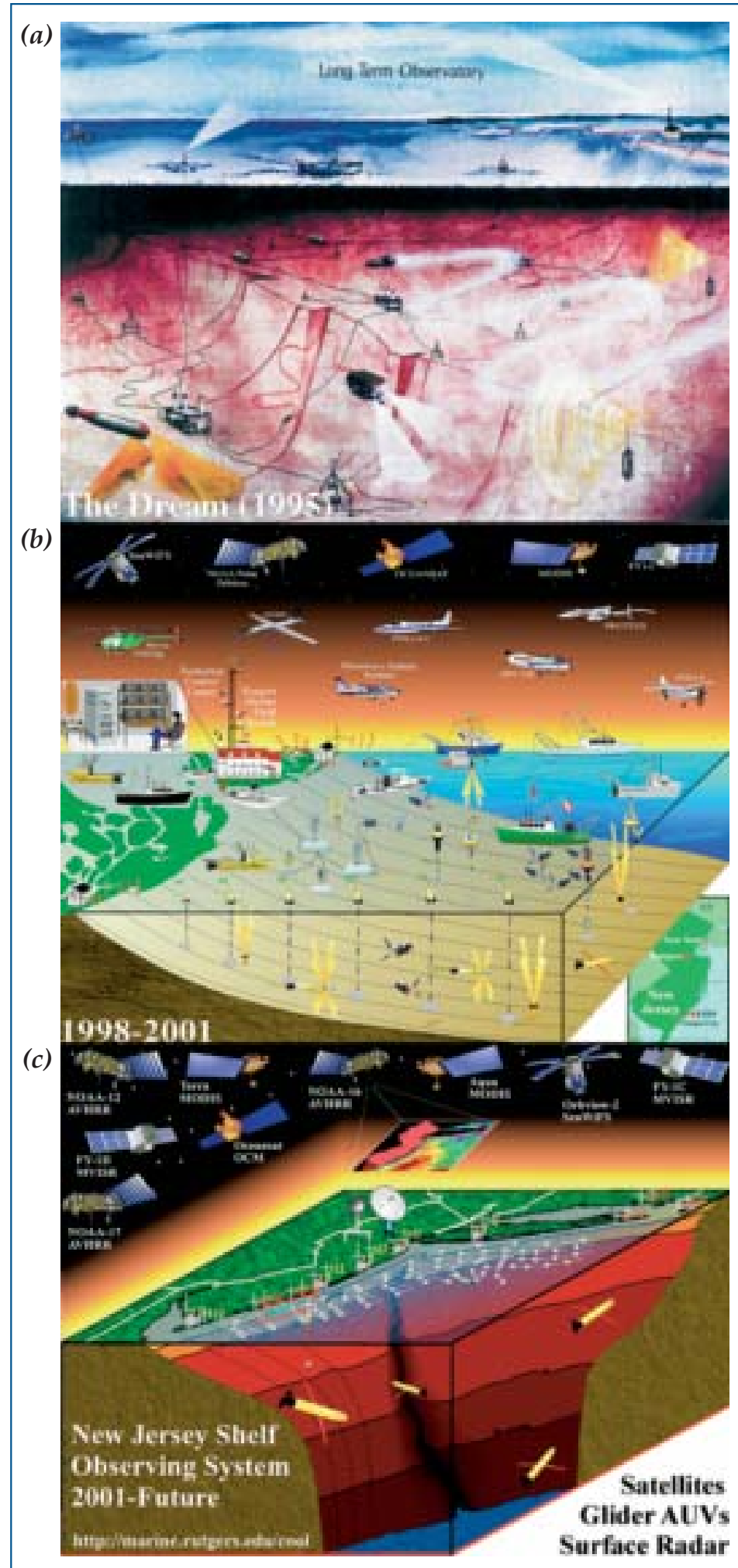

Figure 1. The evolution of a shelf wide observatory from an artist's conception to reality. a) An artist conception of an ocean observatory in 1993 used in the proposal for the Long term Ecosystem Observatory (LEO-15) electro-optic fiber optic cable. b) The LEO system during the Coastal Predictive Skill Experiments conducted in the summers of 1998-2001. c) The evolving New Jersey Shelf Observing System (NJSOS) that is focused on understanding material transport and transformation on the continental shelf. of the east coast inner shelf. Initial biological questions focused on small-scale variability in shellfish abundances and its relationship to the underlying sediment and the physical forcing. Results showed that variations in the physical forcing over the ridge scale where relatively minor, with the biological variability more likely related to the flow/animal/sediment interactions with a spatially varying substrate. Another major focus was on sediment transport processes active on sand ridges. One motivation was that the U.S. Minerals Management Service viewed these sand ridges as a natural resource for beach replenishment projects. A scientific question, one with practical implications, was if a sand ridge is mined, is it a relic feature that mining will deplete, or is it an active and evolving feature that replenishes itself by natural processes over time? While differences in the physical forcing around the ridge were barely perceptible within experimental uncertainties, it was known through theoretical studies (Trowbridge, 1995) that even small perturbations in the flow induced by the ridge could cause variations in a simple sediment transport model that could produce a feedback loop that reinforces the ridge. Thus an improved bottom boundary layer-sediment transport model was sought, requiring high resolution near bottom measurements to resolve mostly vertical gradients to directly measure terms in the dynamical balances. Similar process studies requiring high vertical resolution of flow, sediment and now turbulent parameters continue at LEO today, migrating from self contained deployments, limited by battery power and storage capacity, to deployments on the cabled observatory, where the limitation has switched to instrument calibration issues in a harsh and bio-fouling environment. These ongoing scientific process studies sustained over a decade remain one of the most significant users of the LEO site and are among the greatest successes of the cabled observatory.

Sustained time series measurements with self-contained systems also began at LEO well before the cabled observatory was installed. A motivating science question was to determine the sign of the annual cross-shore sediment transport. More specifically, could we estimate the relative magnitudes of the expected on-shore sediment transport induced by bedload transport and ripple migration (Traykovski et al., 1999) on an almost daily basis and compare it to the larger but less frequent off-shore transport of suspended sediment expected during typical storms from model results (Keen and Glenn, 1995). This question does not require the short 

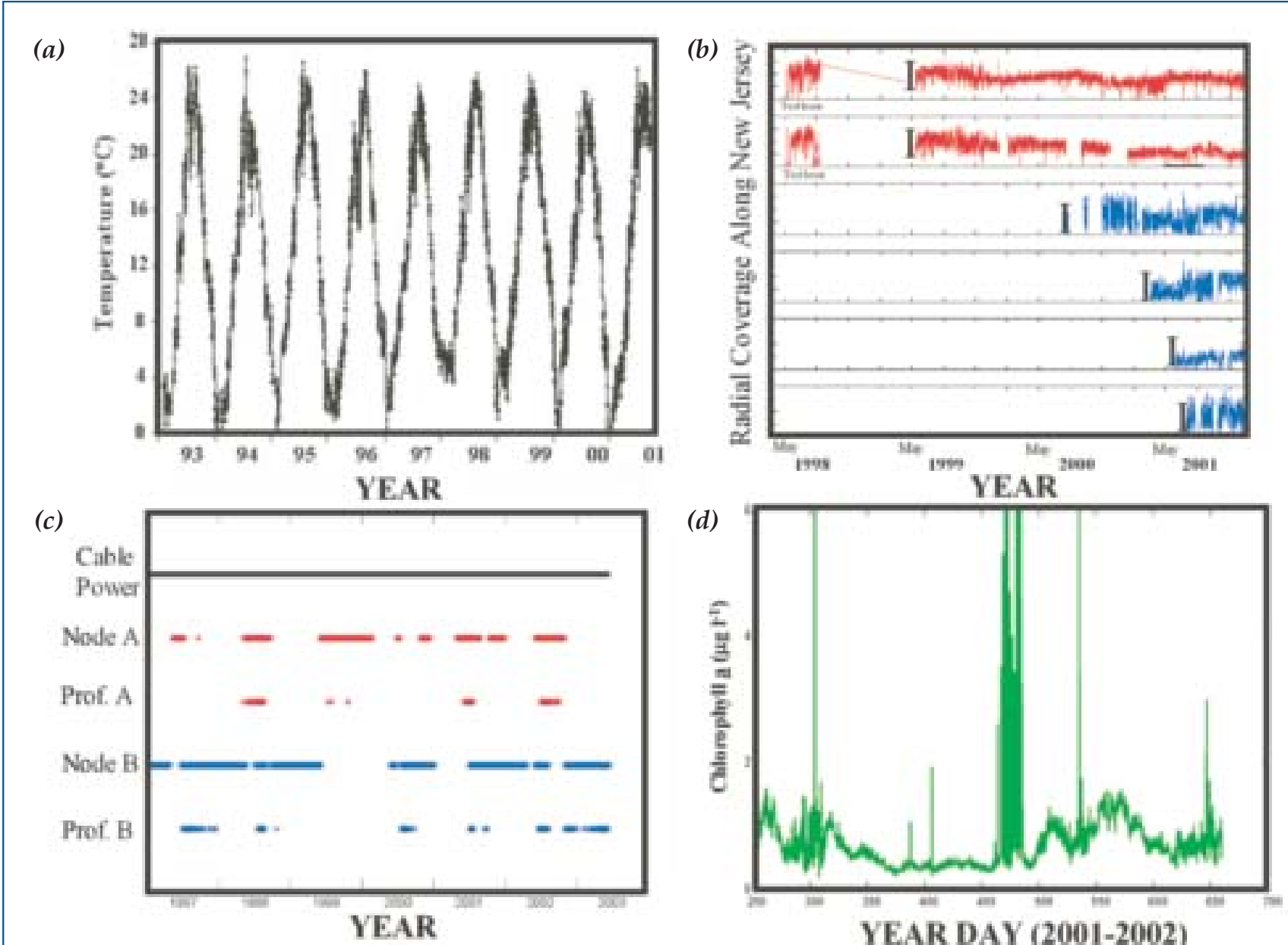

Figure 2. Time series measurements using many of the backbone technologies to ocean observatories. a) A decades worth of sea surface temperature measurements at the LEO site off the coast of New Jersey. $\boldsymbol{b}$ ) Several years of new continuous measurements of surface current radar measurements from sites along the New Jersey coastline. Time series such as these has recently resulted in Coast Guard officially declaring that surface current radar is now a mature technology. The "I" indicates when a specific CODAR site was installed. c) Time series collected with LEO electro-optic cable. Note that while the cable has been extremely successful at delivering power to the sea floor, much work is required in developing a robust capability to profile the water continuously. d) Over a year of time series data from a mooring deployed by the Ocean Physics Lab (University of California at Santa Barbara, Manov et al. 2004). The development of new approaches to combat biofouling has greatly increased the duration that moorings can be at sea and collect scientific quality data.

term but spatially extensive measurements needed to improve the boundary layer models (Styles and Glenn, 2000), but it does require a sustained time series of those observations necessary to drive the models. To our surprise, when the 2-year time series were used to drive the improved bottom boundary layer model (Styles and Glenn, 2000), the resulting cross-shore suspended sediment transport from the long-term measurements was onshore, opposite of what we expected from the models (Figure 3). The suspected reason for the sign difference is believed to be under-resolved topography in the initial 3-d model runs, but at what scale, that of the few kilometer ridge and swale, or is it the larger few tens of kilometer scale of the ancient river deltas present along the southern New Jersey Shelf?
The Coastal Predictive Skill Experiments $(30 \mathrm{~km}$ by $30 \mathrm{~km})$

NOAA's long-term monitoring of dissolved oxygen along the New Jersey coast had documented hypoxic conditions in over $1 / 3$ of the summertime bottom water observations (Pearce et al., 1982; Figure 4). Spatial distributions of hypoxic conditions clustered offshore four different estuaries, leading to the initial hypothesis that perhaps terrestrially-derived organic matter may contribute the organic fuel that eventually leads to depleted oxygen. But both relatively pristine and anthropogenically impacted estuaries were associated with recurrent hypoxia, and some interspersed pristine estuaries were not. Science questions focused on explaining 

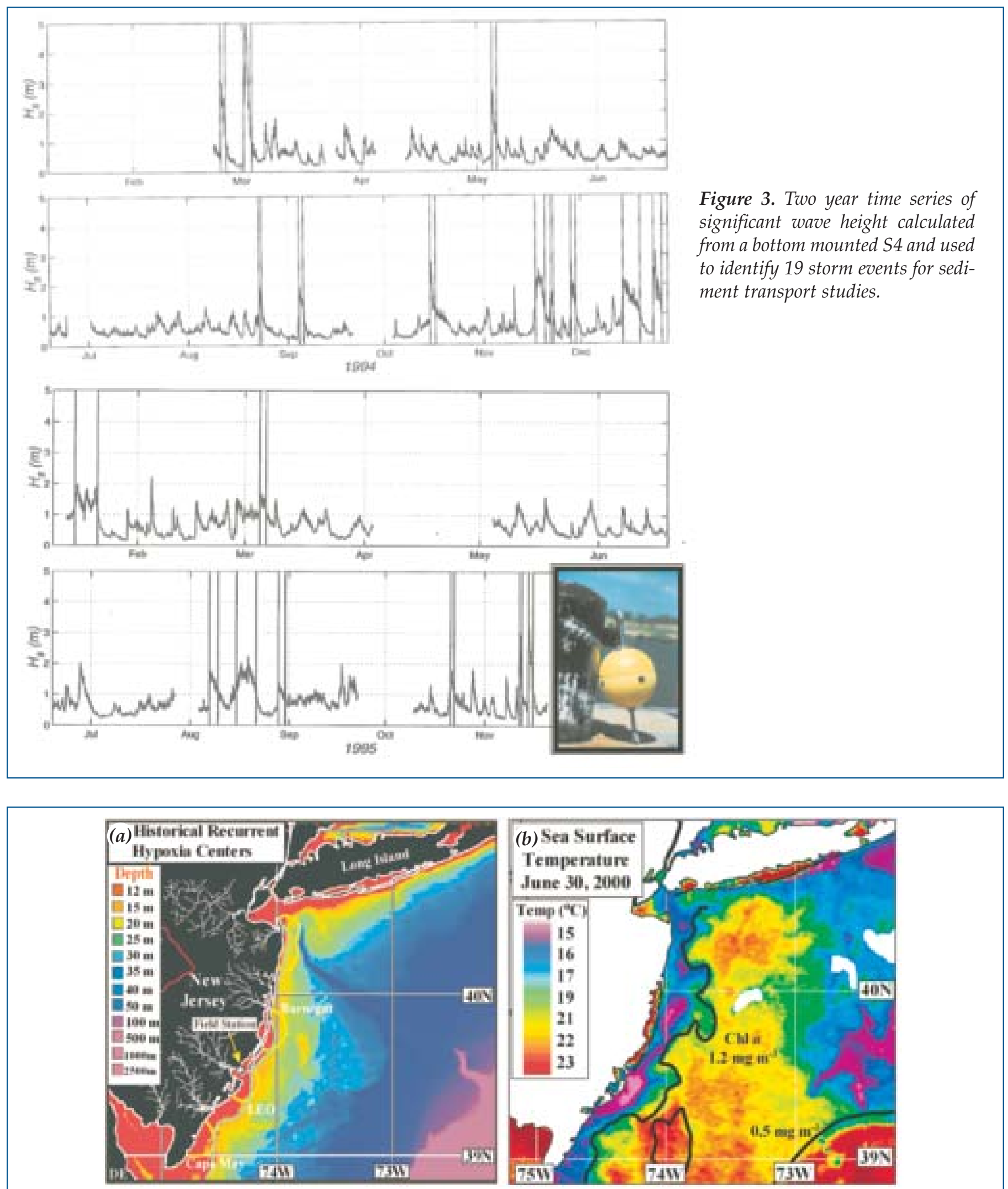

Figure 4. The location of the LEO site along the New Jersey Coast. a) A bathymetry map where the four regions (yellow arcs) of recurrent hypoxia, as defined by NOAA time series (Warsh, 1989), is highlighted. The 13-meter isobath is highlighted in green. Note the peaks of the isobath's offshore extent are offset just to the south of the hypoxic areas. Rivers and streams defining coastal watersheds are shown. b) An AVHRR Sea Surface temperature (SST) image showing multiple upwelling centers along the New Jersey Coast. Two contours showing chlorophyll a values derived from a SeaWiFS image on the same day are superimposed on the SST. The peak chlorophyll values correlate with the low temperature water in the SST image. 


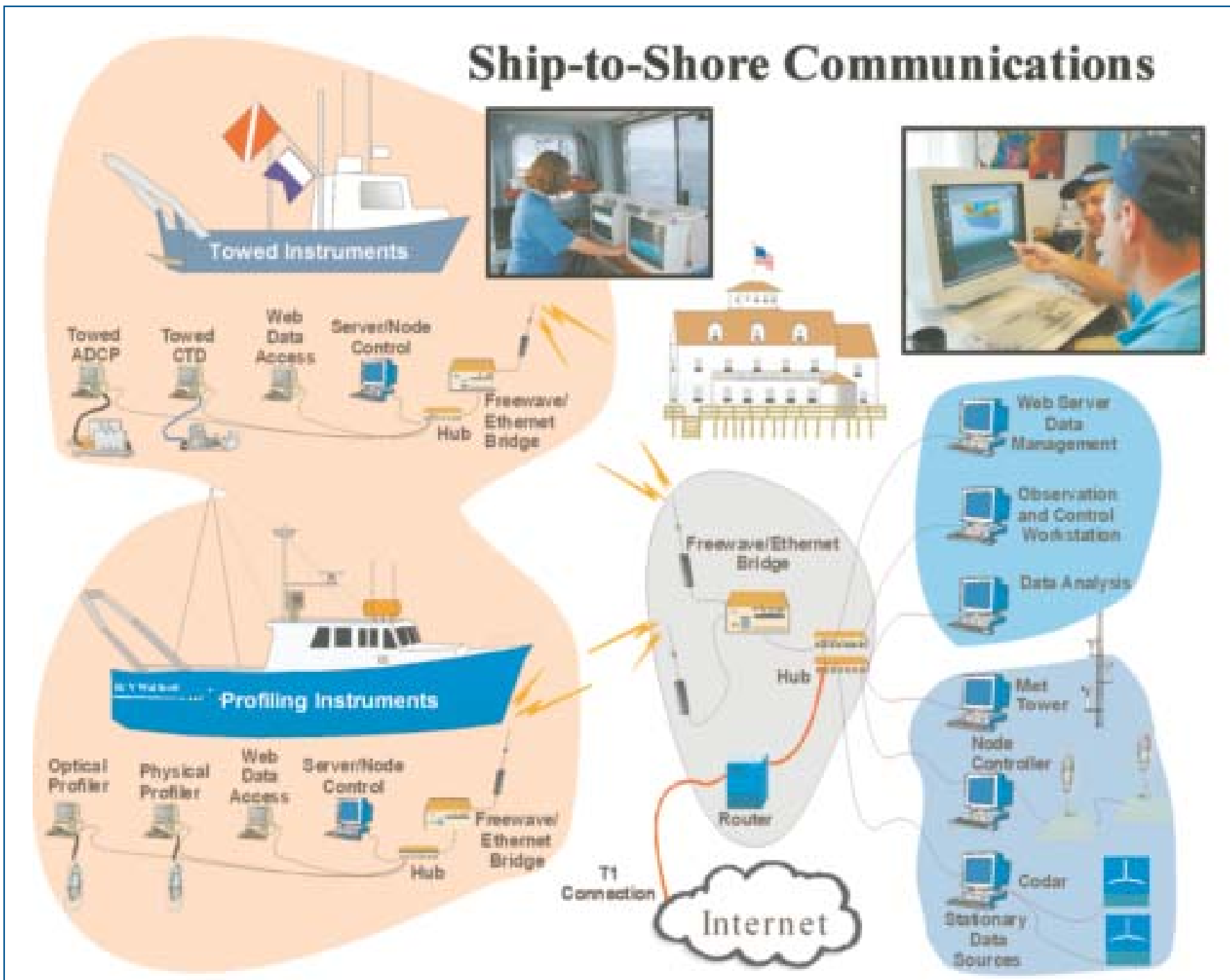

Figure 5. The wireless modem network developed during the coastal predictive skill experiments.

this conundrum. Since the timing of hypoxic conditions often followed upwelling-favorable southerly wind events, we proposed an alternative hypothesis that regions of recurrent hypoxia were more related to coastal upwelling then estuarine outflows, and began studies to determine the structure and evolution of the upwelling response offshore New Jersey. Our objective for developing a nearshore observation network therefore was to resolve a 30 by $30 \mathrm{~km}$ swath of the ocean in order to understand the physical, chemical, and biological processes central to formation of hypoxic waters off southern New Jersey.

Facilitated by the Office of Naval Research and the National Ocean Partnership Program (NOPP), efforts focused on developing a flexible ocean sampling network that was coupled to a numerical nowcast/forecast model. The science-engineering academic partnerships successful at LEO were expanded to similar partnerships with industry and government agencies for implementation. The month long experiment consisted of three- to four-day duration ocean forecasts generated twice a week for a total of 8 forecast cycles using the Regional Ocean Modeling System (ROMS). Biweekly forecast briefings allowed researchers to adaptively plan field efforts. Field observations consisted of real-time satellite remote sensing, standard and long range surface current radar measurements, research vessels, and two classes of underwater vehicles (Schofield et al., 2002). A major addition to the observation network was a wireless communication network based on radio frequency modems that allowed the scientists onshore and on the research vessels offshore to access data from each other (Figure 5) allowing them to adjust sampling patterns and track features being advected within the sampling grid. The ability to rapidly distribute data and provide researchers with a continuous spatial picture of what, when, and where processes were occurring, transformed typically independent field operations into a collaborative effort.

Upwelling along New Jersey was found to often begin as a nearly uniform narrow band of cold water 
along the coast; however, after a few days of persistent wind, or most notably a wind relaxation, a wave pattern forms along the upwelling front that eventually collapses into a series of isolated cold surface patches (Figure 4). These upwelling eddies form year after year offshore the same inlets and estuaries that are associated with recurrent low dissolved oxygen (Figure 4), covering close to a 20 by 20 kilometer swath of ocean. Results demonstrated that a series of topographic highs along the New Jersey coast associated with ancient river deltas (Figure 6) could explain the recurrent formation of these recurrent upwelling centers (Song et al., 2001). Warm water on the offshore side of the front is transported downwind and the eddy temporarily traps the cold water within each upwelling center. Just shoreward of the upwelling front, the raised isotherms are associated with the offshore and northward advection of cold water by the cyclonic eddy. The depressed isotherms in the middle of the upwelling are associated with the onshore and southward advection of warm water by the eddy (Figure 6, Glenn et al., 1996). Associated with the upwelling was an immediate increase in water column turbidity reflecting enhanced concentrations of inorganic/organic particulates and dissolved substances with concentrations sufficiently high to deplete the oxygen in bottom waters. Upwelling response of the bottom did not follow the traditional 2dimensional model, but was clearly 3-d. A strong and narrow nearshore subsurface jet flowing south counter to the prevailing wind was discovered on the adaptive sampling surveys was found to be the likely source of the phytoplankton within the upwelling center (Chant et al, 2003). Results indicate that the high phytoplankton concentrations within the upwelling center are not solely due to the injection of nutrients followed by local growth, but that advection of phytoplankton from outside the sampling domain also plays a significant role (Figure 7).

The focused scientific effort and the adaptive sampling capability attracted a significant number of scientists, engineers, and industry partners (Figure 8). The value of the observatory was that it was an integrated array of synoptic spatial observations allowing scientists to decide what, when and where to sample.

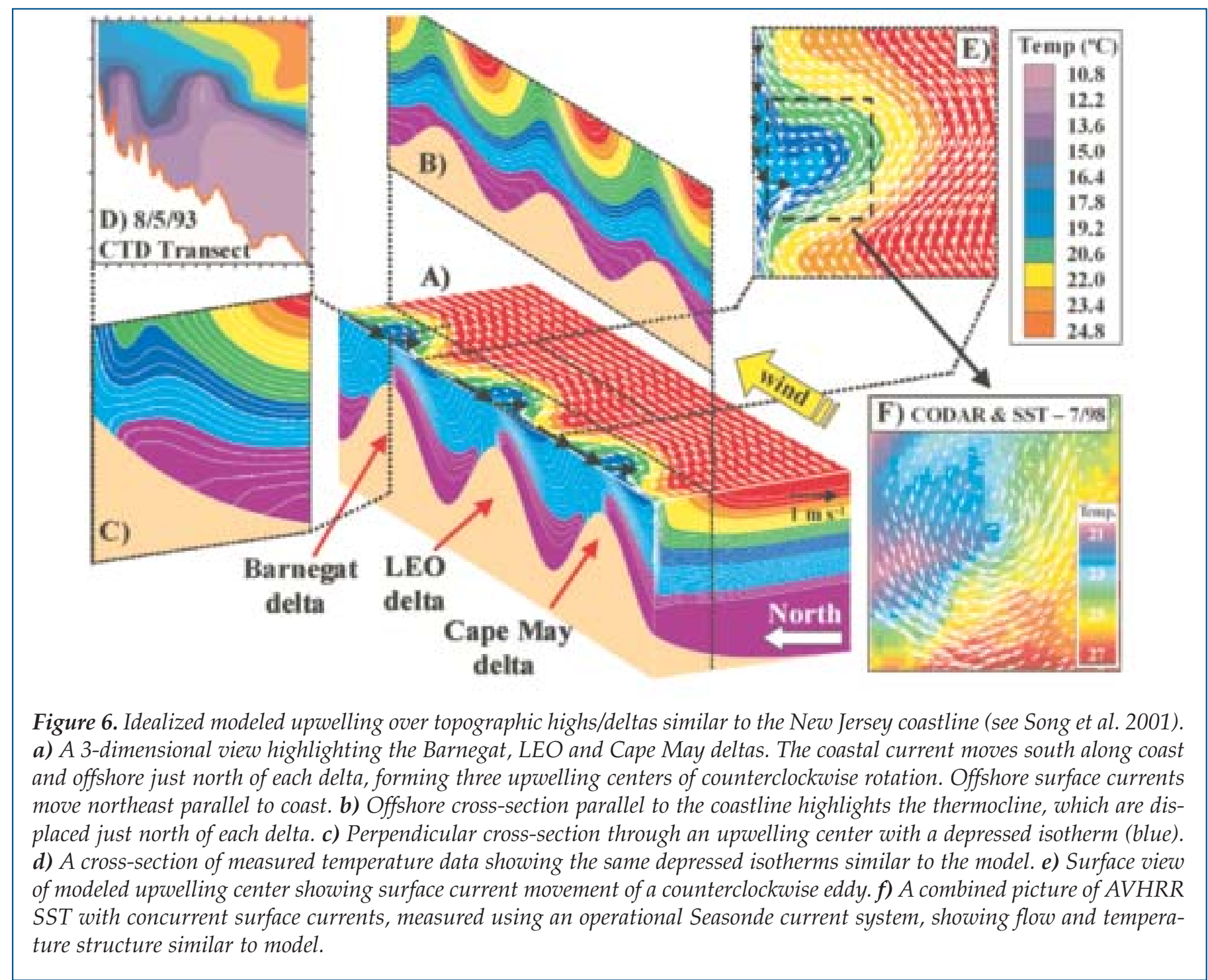



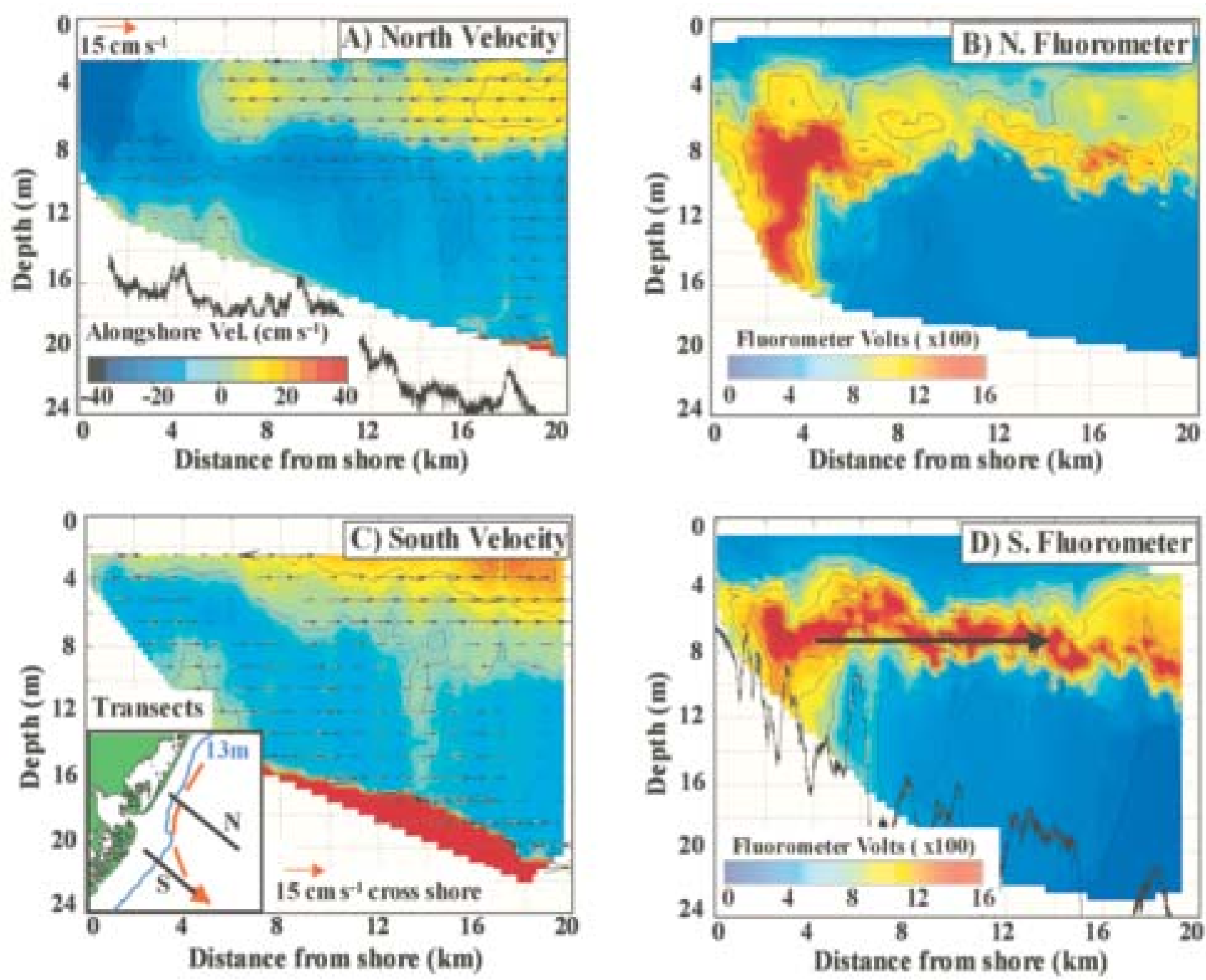

Figure 7. Cross-shelf transects from July 12th, 2001, where data was collected using an undulating Guildline CTD/Fluorometer system and a surface towed ADCP. a) The ADCP velocity cross shelf section taken north of the upwelling eddy (see the inset map in Figure 7c, which is delineated by a southward flowing pipe of water (blue = flow to the south) in the nearshore waters. $\boldsymbol{b})$ The fluorometry cross-section with enhanced chlorophyll values associated with the southward flowing jet. c) A cross-section of current on the southern edge of the upwelling and the pipe is gone and there is enhanced transport offshore (delineated by the arrows). d) The fluorometry cross-section associated with the currents in Figure $7 \mathrm{c}$. Enhanced material is flowing offshore with most material associated with the thermocline, which is below the detection limits of passive ocean color satellites.

Additionally, the observationally rich environment enabled an ensemble of model runs with different initial conditions, boundary conditions and internal parameterizations to improve our understanding of why conditions are changing. Finally, these demonstrations of the various technologies identified which ones were ready for transition to sustained operations over larger regions.

New Jersey Shelf Observing System (300 km by $300 \mathrm{~km}$ )

Efforts to construct a shelf-wide observatory by the now proven NOPP approach began in 2000. While our previous experiences with sediment transport and coastal upwelling both motivated the need for larger scale measurements sustained for at least the seasonal scale, the prospects for a shelf-wide observatory resulted in a much more comprehensive list of research questions (Table 1). The list was assembled through numerous conversations with potential scientific, business and regulatory users of the developing observatory. The challenge for the reader is to decide which research questions were motivated mostly by scientific users, and which were motivated mostly by businesses and regulators. It is our hypothesis that most readers won't be able to tell the difference.

To expand the observatory footprint in a manner that is sustainable within the existing budget constraints of the peer-reviewed system, we have focused 
Table 1.

Questions driving the development of NJ SOS

The following questions were derived from discussions with scientific, business or regulatory users of the NJ SOS. The challenge we pose for the reader is to decide which ones were posed by academics, and which ones were posed by businesses/state regulatory agencies.

Who is the user quiz?

1) How are metal contaminants in industrialized rivers transformed as a river plume flows onto the continental shelf and along the coast, and how is the transformation modified by upwelling/downwelling favorable winds?

2) How does the vertical structure and intensity of the seabreeze vary in both the offshore and onshore directions, what controls its evolution in time, and how is this modified by coastal upwelling and downwelling?

3) What is the spatial and temporal variability in the inflow and oufflow at the mouths of the large east coast bays, and how is these modulated by varying freshwater inflows and wind forcing?

4) Over what time scales does the spatial structure of the seasonal sub-surface cold pool vary, and what is the dominant forcing for this variation?

5) Can knowledge of the evolving spatial current structure be used to determine and eventually predict if fish spawned in a specific reserve area will seed adjacent reserve areas, and which estuary the resulting juveniles will enter?

6) How can observed Eulerian current fields be best transformed into Lagrangian trajectories?

7) How does the onshore/offshore transport of sediment vary along the coast, and how is this affected by different storm types and local topography?

8) How are different phytoplankton blooms (harmful and otherwise) affected by the relative contributions of nutrients from land or from offshore, how does this effect hypoxia, and how does this vary spatially relative to the large highly-populated estuaries?

9) How large of sink or source is the continental shelf for atmospheric carbon?

10) How do the deep canyon features crossing wide continental shelves (e.g., Hudson Shelf Valley and Canyon) disrupt regional flow patterns, and what is the resultant effect on sediment transport and fish species?

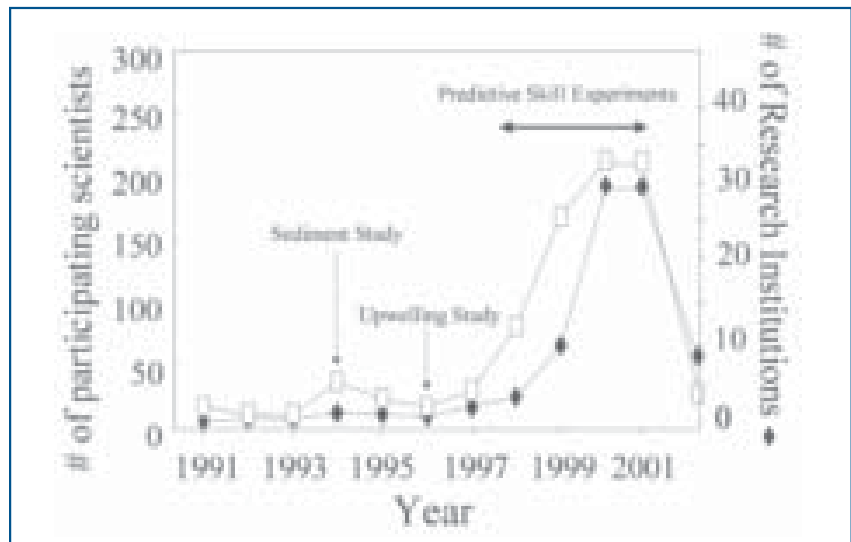

Figure 8. The science activity at LEO over the last decade. Note the large influx of scientists for the coastal predictive skill experiments dropped off after spatial mapping and forecasting demonstration efforts ended. Despite lower numbers, the cabled observatory supports on average 10-20 scientists per year.

on implementing three enabling technologies in collaboration with three business partners. The enabling technologies include: (1) local access to a growing international constellation of high-resolution (spatial and spectral) satellites providing thermal and ocean color maps; (2) multistatic long-range HF Radars generating continuous spatial coverage over distances greater than $200 \mathrm{~km}$ (Figure 9); and (3) a fleet of longduration remotely-controlled Glider-type Autonomous Underwater Vehicles (AUVs) for mobile subsurface physical/bio-optical observations (Figure 10). These mapping tools will be augmented with strategically located, long-duration physical/bio-optical moorings or cabled observatories for subsurface time series at fixed locations. Placement of such single fixed assets works well when located near the center of a water mass so that their results can be expanded spatially. Strategies for studying moving fronts include using moveable assets like gliders to track the features over long time periods, and high-resolution mooring arrays deployed across moving fronts for specific intensive short-term studies. One example of how these systems might work together is to augment the existing nearshore cable located in the middle of an upwelling center with a retired AT\&T telecommunications cable, which extends to midshelf. The hope is to outfit this cable with an instrumented node in the center of the cold pool, giving us a constant time-series in the center of this water mass, and use the gliders to patrol the moving subsurface frontal edges of the cold pool water mass. During short time periods, extensive mooring 


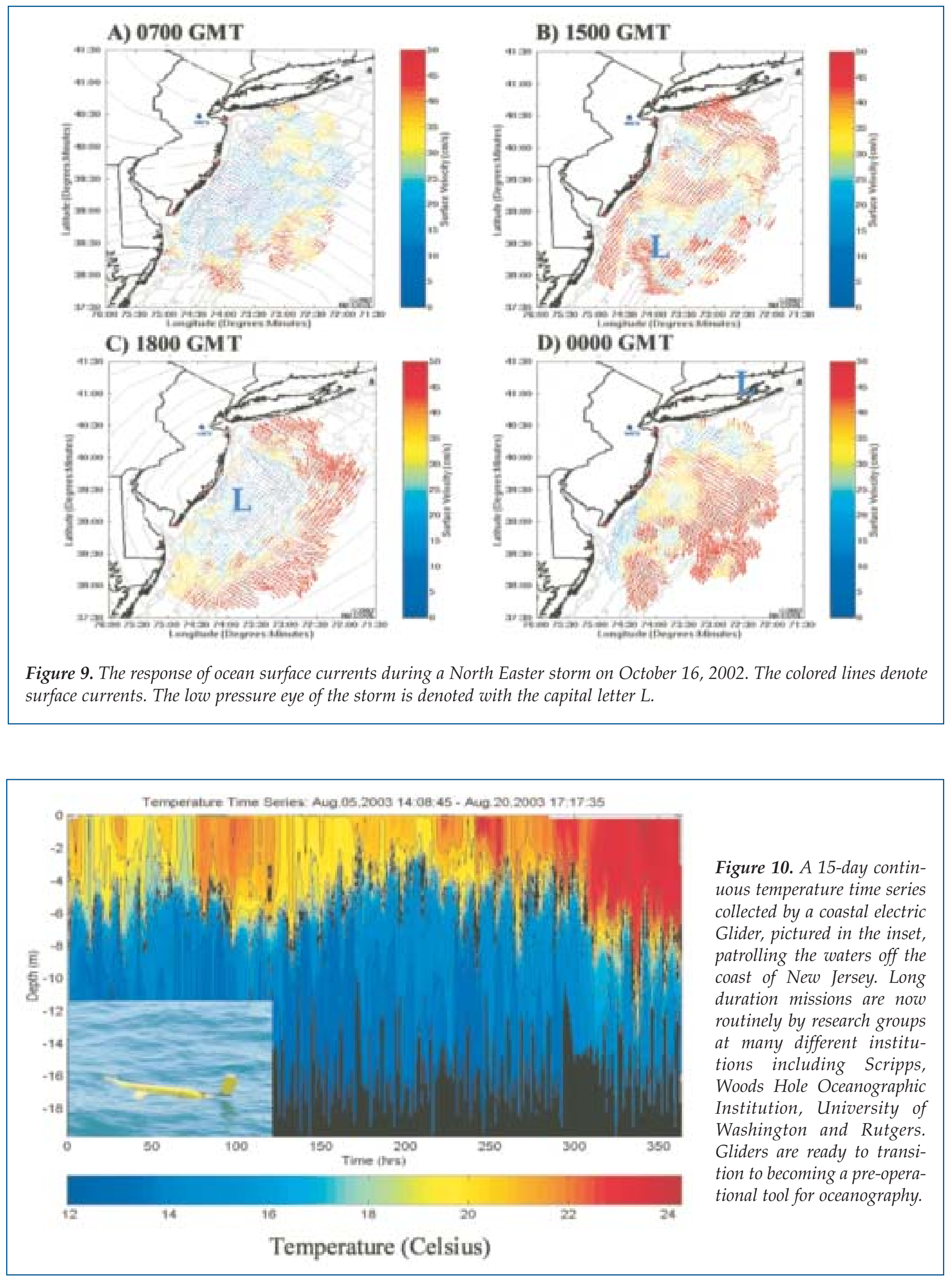




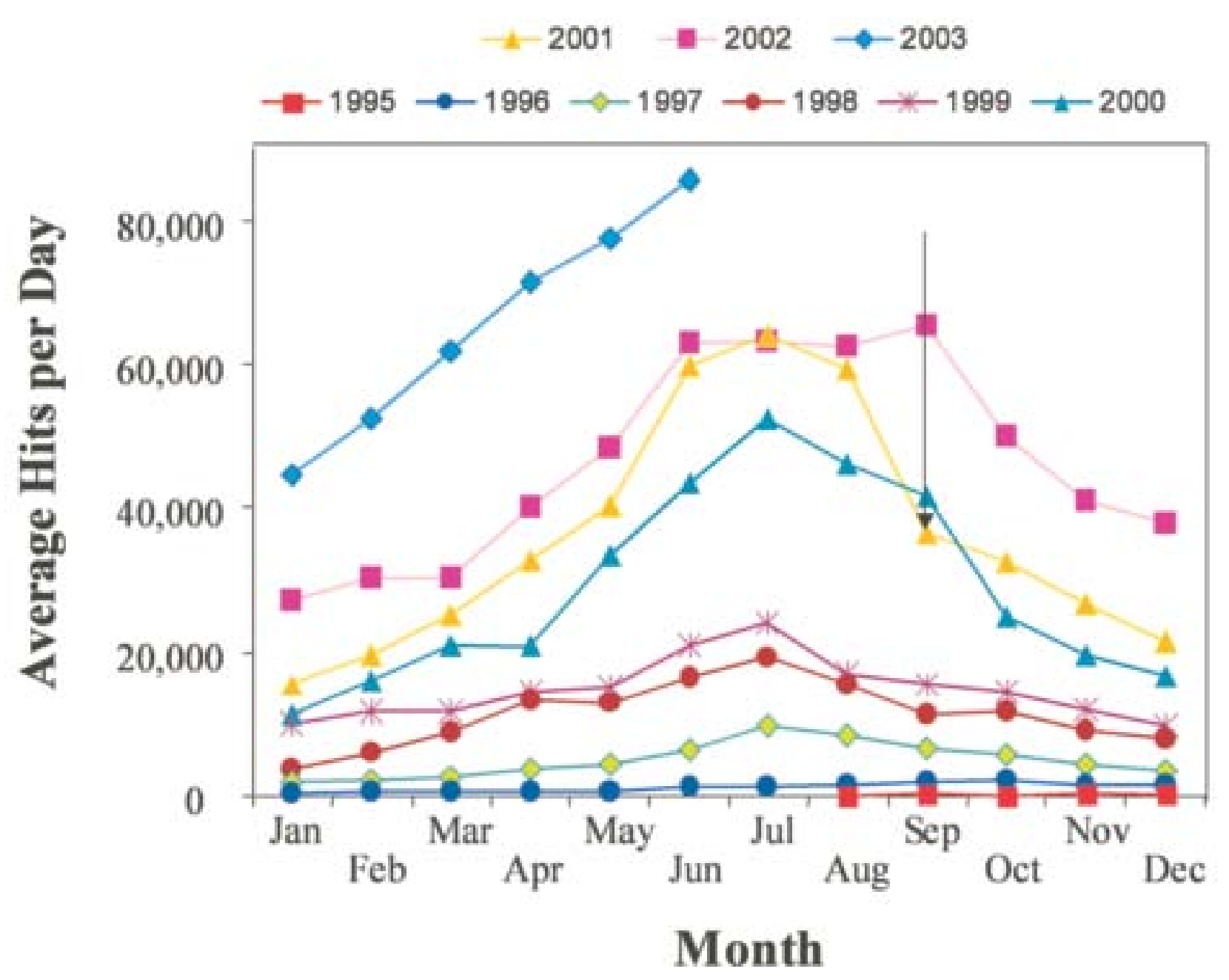

Figure 11. Average daily web hits by month since we began keeping web statistics in 1995. Web access peaks in the summer due to the large increase in recreational users. Web access has grown every year. For a given month, the average daily web hits increase from year to year. A drop was only experienced twice, once in response to September 11, 2001, and the second time in July of 2002, the first July without a Coastal Predictive Skill Experiment. The monthly average web hits accessing data from the NJ SOS. The only decrease was observed during September 11,2001. The data indicates 69\% of the web hits are from the general public, as delineated by AOL domain name. Regional maps (satellites and CODAR) are the major item that is accessed by the general public.

arrays will be deployed for process studies associated with river plumes and with upwelling events. The monitoring plan supports the products required to address some of the questions outlined in Table 1, thus it is product-driven by users from the scientific, regulatory and business communities (see below).

\section{Our Concerns for Ocean Observatories}

Sustained Funding Remains Illusive

Scientists have maintained coastal, bay, and large lake observatories, in some cases for well over a decade, by cobbling together numerous small and short-term research, engineering development, or education grants. One of the greatest energy sinks for observatory scientists is winning and managing these grants. This mirrors the experience of scientists collecting deep ocean data at the Hawaii Ocean Time Series (HOTS) and the Bermuda Atlantic Time Series (BATS) sites, which have been maintained by the efforts of a few stalwarts. Options for sustained funding of the scale necessary to operate an observatory are few. Most research, engineering or education grants from federal agencies are short term and the success is often based on the same publication metrics used by academics. While this system maintains strong peer oversight over the systems (no academic welfare here), it systematically limits our ability to collect scientific time series data. In response to the scarcity of funds, many academics have garnered congressional support for their observatories and the resulting congressional plus-ups and earmarks have 
been effective for setting up the initial infrastructure and operational team; however, congressional plusups often have life-times similar to peer-reviewed grants. State funding for sustained monitoring is usually associated with local environmental concerns and discrete events. Heavily trafficked ports or coastal power plants are common drivers. These often provide an excellent source of long-term support for local observations in response to specific regulatory requirements, but not for regional observations for general use. An option promoted by the successful National Ocean Partnership Program (NOPP) is based on developing partnerships with businesses (see below). In New Jersey, this has resulted in evolving partnerships with the energy industry due to their interest in more efficient use of the overburdened power grid and the promotion of renewable energy development. These partnerships currently show the most promise for providing at least partial sustained support for a regional observation network. This leaves the new initiatives from NSF and the Integrated Ocean Observing System (IOOS). NSF proposes a significant increase in funding through the Ocean Observing Initiative (OOI), but the coastal portion is focused on the development of new relocatable pioneer arrays that would temporarily provide a local enhancement of an observation network for science. It does not sustain any part of the existing or developing national coastal network for science. The IOOS plan to develop a national federation of regional associations of observing systems is by many measures well on the road to success, but its user-driven emphasis has, in our view, under-emphasized the importance of science goals. So, despite the recognition that coastal ocean observatories will serve scientific as well as societal missions, sustained support is still on the horizon.

\section{Narrow Definitions of Observatory Users are Self- limiting}

If IOOS is the most likely route to sustainable funding for coastal observatories, how will the funding be secured? For IOOS, it is quite clear that demonstrating strong user involvement is key. Demonstrating user involvement is difficult and many different models exist.

One model is based on getting users to buy-in to the design of the system, and the governance of the observational assets. The Gulf of Maine Ocean Observing System (GoMOOS) has devoted much energy to exploring this user-driven model, where users provide an annual fee (ranging from $\$ 500$ to $\$ 5000$ ) providing them a seat on the governing board of a non-profit organization that oversees the operation. This approach typically raises on the order of $\$ 100,000$ per year; however, for the nominal membership fee, the user has the privilege of exerting a great deal of influence on how the assets of a \$12 million dollar congressional investment is deployed. The experience of GoMOOS illustrates the vexing issue of how do you quantify a successful userdriven observatory? Should success be considered when users pay a nominal fee or the full market value for the observatory? As many regions in the country do not have access to congressional resources, does this exclude them from implementing the approved user buy-in model for their system? If no congressional investment exists and the observatory is maintained by research grants and partnership priorities that are already fixed, will users be willing to buy-in to a pool that includes only their user fees?

An alternative model can be found at the universities. Academic institutions, especially state universities, have a long history of community involvement and a strong public outreach mandate. Successful outreach, however, is rarely based on financial involvement. Outreach is often achieved through extension agents that are often coordinated through land and sea grant institutions. Additionally many groups have developed effective K-12 outreach teams. Using our own experience as an example, Rutgers has developed a successful outreach program where a primary focus is using observatory data to improve science teaching for public school children. Many outreach groups also distribute observatory products via the world-wide-web. This was one of earliest forms of outreach at Rutgers, and the web site currently averages about 100,000 hits per day during the busy summer months, with most users from the general public (Figure 11). The success of this outreach effort was formally recognized by the New Jersey State Legislature in Assembly Resolution \#209 (http://marine.rutgers.edu/ $\mathrm{cool} /$ news/assemblyresolution209.htm). However, in some IOOS circles, the prevailing view is that this large external user pool is not sufficient evidence of user support. This is often frustrating to the academic who must also quantify impact by peer-reviewed manuscripts and grant awards.

However, we believe these different models are not in conflict, and rigid definitions are counterproductive. Given limited resources, we as a community must leverage the involvement of all groups. We feel this is best accomplished through collaborations not limited to the user-driven model but in true synergistic partnerships at several levels. This is based on our positive NOPP experience, which is the approach we have adopted with our business partners. While research funding remains relatively steady, our business partnerships have resulted in a new and a rapidly growing segment in a more diversified observatory support portfolio. This partnership model has generated on the 


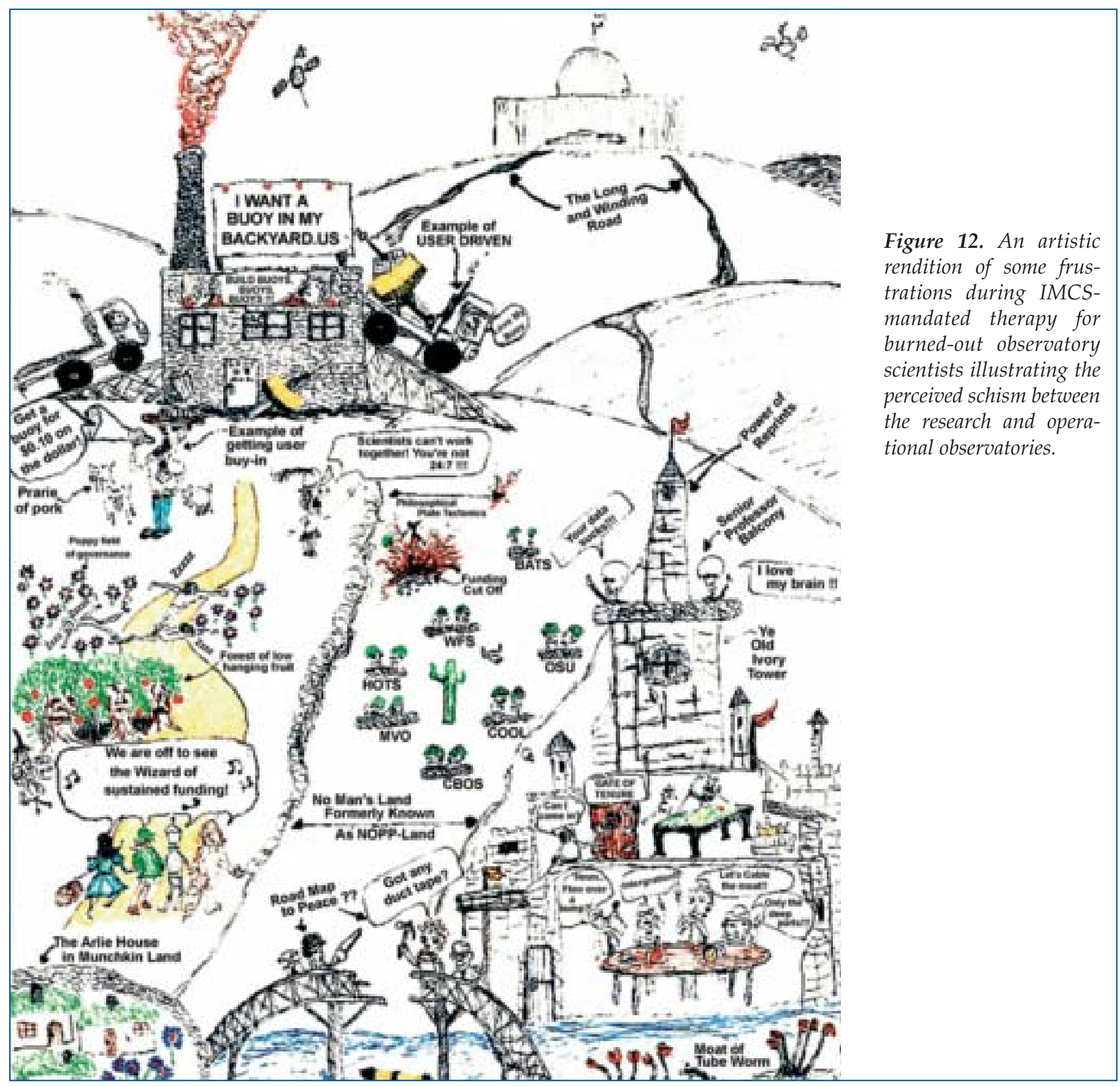

order of $\$ 300,000$ in pilot studies in just the last year through joint efforts with our partners from the power industry. Our partnerships with industry have also spawned effective science-engineering teams (SeaSpace Inc., CODAR Ocean Sensors, Inc., Webb Research Corporation, Inc., WetLabs Inc.) focused on developing new tools for the observatories which we continue to maintain with or without grant support.

\section{Scientist Involvement in Observatories Tends to be Undervalued}

Scientists working in observatories are often battered from both sides of the potential schism between the operational and academic communities. A consistent big picture of the schism has evolved from several observatory scientists recently recommend for art therapy (Figure 12). No matter which side we talk to, we are told the other side doesn't get it.

Starting with the operational side of the schism, we have been told that scientists A) are not 24/7, B) are not collaborative and $C$ ) are either totally replaceable or irreplaceable (both of which are portrayed as bad). The first point is the old stereotype that operations people can't be innovative and scientists cannot sustain any long-term effort. This argument is not based our realities. Close collaborations with our regional NOAA weather service office in Mount Holly have existed for years. The 24/7 NOAA scientists we work with are highly innovative in their search for new products on seabreezes, riptides, and coastal 
upwelling. The same NOAA scientists continue to express their appreciation for the $24 / 7$ datasets we supply that help them generate these products. Scientists, when given the opportunity, are 24/7 because they have a vested interest in collecting continuous long-term datasets allowing them to both document trends and to study specific processes in hindcast mode using historical data. Many operational applications emphasize responses to real-time data whenever it is available. If the data are there, you use them, and if not, you make decisions without them until they return. The Navy calls this process graceful degradation. Thus the data gap affects these operations only at the time of the gap and has very little effect beyond. Scientists from academia, government and industry, however, are one of the biggest users of the historical observatory data. A data gap often haunts the science user who will be continually mining the available data for years to come. Maintaining a continuous data stream for envisioned and sometimes unforeseen studies is highly motivating, prompting scientists to fix things when they break at 5:00 pm on Friday afternoon, and to rush out before the storm hits to make sure everything is working.

The second statement that scientists are not collaborative also is not consistent with our reality. Our experience throughout our careers has been that there are a significant and growing number of scientists who want to tackle interdisciplinary problems most often as part of a collaborative team. Our experience during the Coastal Predictive Skill Experiments at Tuckerton from 1998-2001 (Figure 8) confirms this. We believe it is not a lack of interest in collaborations, but more often the lack of opportunities that may cause this non-collaborative misconception to persist.

How replaceable or irreplaceable are scientists for an operational observatory? The opinion changes and the discussion as whole illustrates that people with experience in developing these ocean networks, whether in academia, industry, or in the government, are a commodity. From the academic perspective, observatories are becoming integral parts of the university research, education and outreach program, so oceanography departments will likely not want to see them fail. The greatest challenges are to avoid burn-out of the academics currently raising the grant-funds to maintain their observatories, and to develop ways to entrain new young scientists without jeopardizing their academic careers.

On the academic side of the schism (Figure 12), many of the observatory scientists routinely endure the Toys-R-Us taunts by fellow academics, that observation is not science. Head on confrontations go nowhere. Instead, we sheepishly acknowledge their concerns in public, and relate these experiences in private as badge-of-honor sea stories shared over the traditional beverages. Why continue? Why don't we retreat to the ivory tower to contemplate great thoughts as our mentors have trained us? Its because we believe that the ocean is chronically undersampled, and that traditional sampling platforms limit what can be documented. Integrated observatories offer the potential to overcome this and collect data that has until now been difficult to attain (for example: impacts of hurricanes on the coastal ocean, see Ocean.US website). While the taunts are draining, they rarely dissuade, as many of us have tenure. Our positions allow us to devote the copious amounts of time required to develop, raise money to maintain, and then use this new infrastructure. The unfortunate side to this is that it has led many of us to wave-off young untenured scientists who would like to be involved. Tenure is generally awarded to scientists by people from within their discipline for making individual contributions to a specific niche in that discipline. The slow process of building an observatory often does not provide the material required for a strong tenure packet. Additionally, many institutions now ask for a percentage contribution to large teamwritten papers, which fundamentally undervalues the collaborative process. This is unfortunate, since the young untenured scientists are a significant positive resource that remains untapped.

Finally, why do we believe that scientists should be part of operational observatories? Much of the technology is still evolving and, more importantly, many of the potential products from the data have yet to be developed. Waiting for technological advances to slow down will delay their installation, while freezing innovation will undercut their future potential. Efforts that focus on maximizing the innovation generated by the collaboration of scientists and engineers, building a structure that enables the sustained operation of a continuously evolving system, and providing the support for scientists to then use the observatory will ensure their involvement.

\section{Lessons Learned \\ Clearly Define the Goals}

Why do we need ocean observation networks? To quote everyone's grade school teacher, we need to know what, where, when, and if we are really clever, why? The great potential of the ocean observatories is that they can fulfill these scientific needs while simultaneously serving these same societal needs. So how do "we" presently design our observatories to fulfill user's needs? A common approach, used at countless meetings, is to construct long lists of variables and ask users which ones they want. We tally up the scores, and usually find a few common variables reach the 
top. This has been a very useful exercise, however, it only answers the first question-"what?" A user driven success has to be more than deploying a buoy with sensors for the top few variables in a user-specified operations area. Getting beyond "what" requires interactions with users on an ongoing basis.

If you go on to broach the "where" question with users, you quickly find out that users would like much more than local data. Regional data provides a spatial context for what is happening in their operations area. Users prefer to look at a map showing the spatial distributions and how they are evolving in time. This has been demonstrated through world-wide-web hit statistics where users of the observatory log in everyday to plan business or personal needs (Figure 10). The user-driven success of software mapping tools to display data or model output relative to the coast further demonstrates the desire of users to place observations in a spatial context. Just as we are all used to viewing evolving weather maps, scientists at our own Coastal Predictive Skill Experiments found the most useful visualization tool for the 4-dimensional model results to be maps of where the surface and bottom waters were flowing animated in time.

Knowledge of how things are evolving in time leads users to the question of "when". They would like to know when events of interest are happening, and they are especially grateful if they can get that information in real-time; however, the users will also tell you, if you really want to have an impact, tell us when the event will happen tomorrow. This knowledge would allow them to plan ahead rather than simply react to the present. But this requires a forecast, which implies some understanding of the processes, and the inputs that control it, which gets us to the "why" question. This is also the fundamental effort for the scientist in the field, like those at Tuckerton studying upwelling and its relationship to hypoxia. Answers to the most difficult but largest potential payoff "why" question may require measurements at a different places and times than initially expected. This is easy to relate to any user, simply by reminding them that quite often, if they want to know tomorrow's weather, they can start by looking upstream to the west. Thus, through extended conversations with business and regulatory users, we have discovered we both want the same information, namely, "what, where, when and why".

\section{Maximize Collaborative Partnerships}

We have found that distrust and misunderstanding between all the parties involved in sustained ocean observations is not chronic if both sides are willing to invest in the effort. Much of our present success today can be traced back to partnerships initiated through the
NOPP process. Through NOPP, we learned the value of collaborations between academic, government and industry partners. Several of those partnerships have been self-sustaining long after the initial NOPP grant expired. Other new partnerships are being formed under the same model even without NOPP support. One, of several, recent examples is our growing relationship with the businesses and regulators of the power industry who feel that they have much to gain from a predictive capacity for the coastal ocean whose behavior directly impacts their bottom line. Potential gains could be achieved by tapping a renewable energy resource or by improving energy forecasts during specific weather events. The importance of power delivery is underscored by this last summer's blackout in the northeast that emphasizes the need to improve the grid. Providing adequate and reliable power to rapidly expanding shore locations is a significant challenge for New Jersey, since the power grid to the shore is already built out and near capacity. Renewable energy sources are being sought that are capable of providing energy locally during times of peak demand. With the greatest need at the shore, the power industry is a natural user of data collected from the coastal observatories. Power industries and the state regulators in New Jersey, however, do not picture themselves as operators of the observatories, and even question their need to be on a board that governs their operation. The power companies are about as interested in overseeing an ocean observing system as we are interested in overseeing an offshore wind or tidal energy farm. They want to use our data, and we want to use their electricity and platforms, and we trust that each of us are fully capable of running our side of the operation.

So where are the business and regulatory agencies eager to work together with scientists? The IOOS has three major components, (1) an observation network, (2) a communications and data archiving network, and (3) a product generation component. Our experience is that the businesses and regulators trust us to collect the data, transmit it to shore and archive it. Where they want to participate, and are willing to pay the full market value of that participation, is on product development. Sometimes the new products result in the need for new measurements or improved communication/archiving capacities, for which the participants are again willing to pay the full market value. The result is a product-driven enhancement to the observation network. Sometimes those products have overlapping users willing to share the cost. Often the users are willing to locally enhance the network to improve the product in specific regions for specific purposes. Sometimes those users are scientists who will locally enhance an observatory for process studies (for exam- 
ple, NSF is augmenting NJSOS with an X-band satellite data acquisition system for the Lagrangian Transport and Transformation Experiment, LaTTE). Business users may wish to locally enhance the network during critical seasons (like power companies during the summer air conditioning season). The important point is that something has to be sustained and in place so that the enhancements are easy and transparent for the user to implement. Set-up and break-down costs for observatory enhancements can be significant, so some partnership efforts may find it less expensive to maintain their upgrade continuously.

\section{Human Resources are the Most Scarce}

Since the late 1990s, a common conclusion of several workshops on observing systems is that we currently lack the increasing number of technically trained personnel required to operate the rapidly evolving observation network. The common recommendation is the need to train more Bachelors and Masters level students in the operational aspects of observatories without negatively impacting existing Ph.D. programs. Results of a recent community workshop on cabled observatories noted that we also lack a sufficient number of leaders with both the scientific and organizational skills to oversee the operations of the numerous observatory efforts. Ph.D. scientists are usually taught through their thesis research to pursue in depth a single-minded focus in relative isolation, while observatory management is requires experience in a multi-tasking environment that requires team-building skills. As human resources are scarce at both the leadership and implementation levels, the community as a whole needs to work together. Universities operating observatories serve as the training ground for this next generation of observatory leaders and operators.

\section{Conclusions}

\section{Minimize the Differences Between IOOS and OOI}

Borrowing directly from the playbook of one of the federal champions of the observatory efforts, in the spirit of collaboration, we should recognize that observations in the coastal ocean are not going to be $100 \%$ from an observatory, and they are not going to be $100 \%$ from an observing system (noting few of us in the trenches appreciate the difference). The systems are not going to be operated $100 \%$ by government, $100 \%$ by academics, or $100 \%$ by industry. The operation will not be $100 \%$ user-driven, nor will it be $100 \%$ sciencedriven. All these envisioned systems will collecting valuable data in a sometimes hostile and unforgiving environment. The tables and diagrams that are used to emphasize the differences between IOOS and the OOI often leave the scientists feeling they must choose between one or the other. We should choose to support both, since we are measuring the same ocean. The challenge is to maximize the impact of both by working together. Through these synergistic efforts, the whole will be greater then the sum of the parts. It is not a "win-win" implying two negotiating sides; it is a "big win" for the whole community.

\section{Minimize the Geographic Boundaries}

As coastal oceanographers, we are used to working in our own backyards. Even in the northeast with its small states, and its state and private universities, there was always plenty of ocean for everyone to cover without any overlap. But new technologies are now enabling us to sample larger parts of the ocean. Numerical models are sufficiently accurate and fast that they now benefit from data over large areas. The science questions we are beginning to ask really don't care much about state or regional boundaries. In the northeast, we find it hard to separate the large bays from the continental shelf. Systems are sufficiently mobile that they can be brought to different locations. Systems are autonomous, so they can run while the scientist is somewhere else. Global communications like Iridium allow assets to be monitored and controlled wherever their location. This last August, more glider AUVs were simultaneously patrolling our coastal waters than ever before. While in Monterey Bay multiple gliders were being flown in formation in a single location, we were flying individual gliders in multiple locations in different states. HF Radar is an important spatial mapping tool that is ready for a national presence. How are these being operated presently? Teams of collaborating scientists are constructing the national CODAR array. We have built up a network off the New Jersey coast. In collaboration with the uniformed Coast Guard, systems are being installed on Nantucket. In collaboration with Mote Marine Laboratory and USF we will soon operate a system in Florida. Scientists at Rutgers, URI and U. Maine have collaborated on a temporary installation of a GoMOOS Radar on Block Island to fill the gap between Nantucket and Sandy Hook. This collaboration is notable as it was installed by scientists in response to the few day forecast of the arrival of Hurricane Isabel. The effort was motivated not by a contract, but by a quest for knowledge.

\section{There is Plenty of Work for Everyone}

For the work that needs to be accomplished, there is not enough time in the day for any one person or group. For the current academic observatories, the time sink is not in operations, teaching, or using the data for research, it is in the raising of the operational funds. This might change in the future, but regardless it will be an adventure for all those involved with 
the oceans. The community is now embarking on the implementation phase of a new vision for the future. Large initiatives such as the OOI and IOOS will make this possible and success will require all of our resources and people. Observatory scientists will likely concur that we are spending too much time raising and coordinating small pots of money or sitting through endless governance discussions in the hope of gaining sustained support. Hopefully we will soon recognize that this is an inefficient use of our most scarce resource, namely, the people that make up our community. Its time to let the scientists do what they do best, namely, to continue developing the new sensors, systems and models that we will be using, and to continue putting them in the water for scientific as well as societal purposes, which if we look, are not that different.

\section{Acknowledgements}

Federal sponsors include the National Science Foundation, the Office of Naval Research, the NOAA National Undersea Research and EcoHAB Programs, the National Ocean Partnership Program, the DoD Counterdrug Technology Development Office, and the U.S. Coast Guard. Our long-standing technology development partners include SeaSpace, CODAR Ocean Sensors and Webb Research Corporation. Our growing list of product development partners include the New Jersey Board of Public Utilities, the New Jersey Department of Environmental Protection, Conectiv Power Delivery, General Power \& Utilities, Reliant Energy, Public Service Electric \& Gas, and Bear Technologies. We further thank the Assembly of the Great State of New Jersey for their vote of confidence. But most importantly, we want to thank the real heroes of the COOLroom, namely, the people in the field. We are proud to be part of that team.

\section{References}

Creed, E.L. and S.M. Glenn, 2000: Real-time transmission between research vessel and shore command center. OCEANS 2000 MTS/IEEE Conference Proceedings, Providence, RI, Vol. 2, 1153-1157.

Creed, Elizabeth L., S.M. Glenn and R. Chant, 1998: Adaptive sampling experiment at LEO-15. MTS Ocean Community Conference '98 Proceedings, Baltimore, MD, Vol. 1, 576-579.

Glenn, S.M., M.F. Crowley, DB. Haidvogel and Y.T. Song, 1996: Underwater observatory captures coastal upwelling off New Jersey. Earth in Space, 9, 9-11.

Keen, T.R. and S.M. Glenn, 1995: A coupled hydrodynamic-bottom boundary layer model of storm and tidal flow in the Middle Atlantic Bight of North America. J. Phys. Oceanogr., 25, 391-406.

Kirkpatrick, G.J., C. Orrico, M.J. Oliver, M.A. Moline and O. Schofield, 2003: Continuous real-time determination of hyperspectral absorption of colored dissolved organic matter. Applied Optics, 42, 42, 6564-6568.

Kohut, J.T., S.M. Glenn and D.E. Barrick, 1999: SeaSonde is integral to coastal flow model development. Hydro International, 32-35.

Kohut, J.T. and S.M. Glenn, in press: Improving HF radar surface current measurements with measured antenna beam patterns. J. Atmos. Oceanogr. Tech.

Manov, D.V., G.C. Chang and T.D. Dickey, in revision: Methods for reducing biofouling of moored optical sensors. J. Atmos. Oceanogr. Tech.

Moline, M.A., R. Arnone, T. Bergmann, S. Glenn, M. Oliver, C. Orrico, O. Schofield and S. Tozzi, 2003: Variability in spectral backscatter estimated from satellites and its relation to in situ measurements in optically complex coastal waters. J. Int. Remote Sensing, in press.

Pearce, J.B., C.R. Berman, Jr. and M.R. Rosen, 1982: Annual NEMP report on the health of the northeast coastal waters. NOAA Technical Memorandum NMFS-F/NEC-35, Northeast Fisheries Center, Woods Hole, MA.

Schofield, O., T. Bergmann, W.P. Bissett, F. Grassle, D. Haidvogel, J. Kohut, M. Moline and S. Glenn, 2002: The Long-Term Ecosystem Observatory: An Integrated Coastal Observatory. J. Oceanic Engng., 27(2), 146-154.

Schofield, O., W.P. Bissett, T.K. Frazer, D. IglesiasRodriguez, M.A. Moline and S. Glenn, 2003: Development of regional coastal ocean observatories and the potential benefits to marine sanctuaries. Marine Technology Society, 37, 54-67.

Song, T., D.B. Haidvogel and S.M. Glenn, 2001: Effects of topography variability on the formation of upwelling centers off New Jersey: A theoretical model. J. Geophys. Res., 106(C5), 9223-9240.

Styles, R. and S.M. Glenn, 2000: Modeling stratified combined wave-current bottom boundary layers. J. Geophys. Res., 101, 24,119-24,139.

Traykovski, P., A.E. Hay, J.D. Irish and J.F. Lynch, 1999: Geometry, migration, and evolution of wave orbital ripples at LEO-15. J. Geophys. Res., 104(C1), 1505-1524.

Trowbridge, J., 1995: A mechanism for the formation and maintenance of shore-oblique sand ridges on storm-dominated shelves. J. Geophys. Res., 100, 16,071-16,086.

Warsh, C., 1987: NOAA's northeast monitoring program (NEMP): A report on progress of the first five years (1979-84) and a plan for the future. NOAA Technical Memorandum NMFS-F/NEC-44, Northeast Fisheries Center, Woods Hole, MA. 